\title{
Target DNA- and pH-responsive DNA hydrogel-based capillary assay for the optical detection of short SARS-CoV-2 CDNA
}

\author{
Ji Yun Jeong ${ }^{1} \cdot$ Ji Yoon Do ${ }^{1} \cdot$ Cheol Am Hong ${ }^{1}$ (i)
}

Received: 23 August 2021 / Accepted: 7 December 2021 / Published online: 23 December 2021

(C) The Author(s), under exclusive licence to Springer-Verlag GmbH Austria, part of Springer Nature 2021

\begin{abstract}
DNA is recognized as a powerful biomarker for clinical diagnostics because its specific sequences are closely related to the cause and development of diseases. However, achieving rapid, low-cost, and sensitive detection of short-length target DNA still remains a considerable challenge. Herein, we successfully combine the catalytic hairpin assembly (CHA) technique with capillary action to develop a new and cost-effective method, a target DNA- and pH-responsive DNA hydrogel-based capillary assay, for the naked eye detection of $24 \mathrm{nt}$ short single-stranded target DNA. Upon contact of target DNA, three individual hairpin DNAs hybridize with each other to sufficiently amplify Y-shaped DNA nanostructures (Y-DNA) until they are completely consumed via CHA cycling reactions. Each arm of the resultant Y-DNA contains sticky ends with i-motif DNA structure-forming sequences that can be self-assembled in an acidic environment (pH 5.0) to form target DNA- and pH-responsive DNA hydrogels by means of i-motif DNA-driven crosslinking. When inserting a capillary tube in the resultant solution, the liquid level inside clearly reduces due to the decrease in capillary force induced by the gels. In this way, the developed assay demonstrates sensitive and quantitative detection, with a detection limit of approximately $10 \mathrm{pM}$ of $24 \mathrm{nt}$ short complementary DNA (cDNA) targeting SARS-CoV-2 RNA genes at room temperature within $1 \mathrm{~h}$. The assay is further shown to successfully detect target cDNA in serum, and it is also applied to detect several types of target sequences. Requiring no analytic equipment, precise temperature control, or enzymatic reactions, the developed DNA hydrogel-based capillary assay has potential as a promising naked eye detection platform for target DNA in resource-limited clinical settings.
\end{abstract}

Keywords Catalytic hairpin assembly $\cdot$ Capillary assay $\cdot$ Naked eye detection $\cdot$ SARS-CoV-2 cDNA $\cdot$ DNA hydrogels

\section{Introduction}

DNA sequences are among the most attractive biomarkers for clinical diagnostics as they are closely associated with the cause and development of various diseases such as cancers and genetic disorders [1-4]. The rapid and accurate detection of specific DNA sequences, referred to as target DNA, is therefore critical for achieving effective patient care. Currently, the most widely used method for detecting target DNA is the quantitative real-time polymerase chain reaction (qRT-PCR). This method, though, requires expensive reagents (e.g., enzymes and fluorescent probes)

Cheol Am Hong

cahong@yu.ac.kr

1 Department of Biochemistry, Yeungnam University, 280 Daehak-ro, Gyeongsan-si, Gyeongsangbuk-do 38541, Republic of Korea and equipment, appropriate primer designs, and complex and time-consuming steps, all of which limit its application in point-of-care (POC) testing and resource-poor settings. Moreover, short target DNA with less than 30 nucleotides is extremely challenging to precisely detect due to the low binding affinity of the primers [5]. In recent years, the catalytic hairpin assembly (CHA) cycling reactions have been introduced as an alternative strategy for detecting short target DNA due to the efficient, rapid, and isothermal enzymefree nature of the reactions [6]. Single-stranded target DNA serves as a trigger and a signal amplifier to generate a large number of self-assembled DNA products from catalytic hairpin DNAs. These amplified DNA products can then be incorporated into a variety of detection techniques including colorimetry [7-9], fluorescence [10-12], chemiluminescence [13, 14], and electrochemistry [15], providing for convenient and sensitive detection of very low abundance target DNA. But despite such advantages, specific and expensive 
instruments are often still required, and therefore, the development of enzyme- and instrument-free sensing systems is in demand for cost-effective POC diagnostics.

Capillary tubes are inexpensive and disposable products, commonly used in medical fields to collect a certain amount of sample. Recently, capillary action-based assays have been widely explored as simple, fast, and cheap optical sensors to detect a variety of targets such as nucleic acids and small molecules [16]. These sensing assays are based on the sol-gel transformation in specific response to target molecules in solution using nucleotide-grafted polymers [17-19]. However, the synthesis of nucleotide-grafted polymers requires multiple complex procedures, which may increase the cost of capillary-based testing for practical applications.

In this study, we present a simple, rapid, sensitive, and low-cost method, referred to as the target DNA- and $\mathrm{pH}-$ responsive DNA hydrogel-based capillary assay, for the naked eye detection of $24 \mathrm{nt}$ short complementary DNA targeting SARS-CoV-2 RNA genes. To our knowledge, this is the first time that CHA cycling reactions and capillary action have been combined for the detection of short-length target DNA without the need for enzymatic reactions, polymers, or specific equipment. In the presence of target DNA, three catalytic hairpin DNAs self-assemble with each other to continuously generate Y-DNA products until they are completely exhausted. The resultant Y-DNA contains cytosine (C)-rich sticky ends on each arm, providing a building block to form $\mathrm{pH}$-responsive DNA hydrogels under acidic conditions via intercalated-motif DNA (i-motif DNA)-driven selfassembly. The formation of DNA hydrogels in solution can significantly increase the water retention capacity, leading to an effective decrease in the capillary action-induced liquid rise when a capillary tube is inserted into the solution. In this way, the developed assay can be utilized as a promising naked eye detection platform for POC diagnostics.

\section{Experimental}

\section{DNA oligonucleotides}

All DNA oligonucleotides were obtained from Bioneer Inc. (Daejeon, Republic of Korea), dissolved thoroughly in $1 \mathrm{X}$ phosphate-buffered saline (PBS) containing $137 \mathrm{mM} \mathrm{NaCl}_{2}$, $2.7 \mathrm{mM} \mathrm{KCI}, 10 \mathrm{mM} \mathrm{Na}_{2} \mathrm{HPO}_{4}$, and $1.8 \mathrm{mM} \mathrm{KH}_{2} \mathrm{PO}_{4}$ at $\mathrm{pH}$ 7.4 , and then stored at $4{ }^{\circ} \mathrm{C}$ for further use. The sequences are shown in Table S1.

\section{Design and confirmation of Y-DNA with C-rich sticky ends}

The Y-shaped DNA nanostructures (Y-DNA) with C-rich sticky ends were designed to be synthesized by
CHA-mediated reactions of three individual hairpin DNAs (HDs) using NUPACK software (http://www.nupack.org). To prepare the Y-DNA, three HD solutions (HD1, HD2, and HD3) were heated to $94{ }^{\circ} \mathrm{C}$ for $5 \mathrm{~min}$ and then rapidly cooled to $10^{\circ} \mathrm{C}$ using a thermal cycler (BIOER, China) to form stable hairpin nanostructures. The resultant HDs were mixed together in equal molar ratios and then incubated with the target DNA for $1 \mathrm{~h}$ at room temperature. The final products, Y-DNA, were verified by $8 \%$ polyacrylamide gel electrophoresis (PAGE) in TAE (Trizma base, acetic acid, and $0.5 \mathrm{M}$ EDTA, at $\mathrm{pH} 8.0$ ) buffer at $150 \mathrm{~V}$ for $40 \mathrm{~min}$. The gel was stained with GelRed ${ }^{\circledR}$ (Biotium, USA) for $1 \mathrm{~min}$ and visualized using a GelDoc Go system (Bio-Rad, USA). The band intensities were quantitatively compared using GelDoc Go image software (Bio-Rad, USA).

\section{Formation and confirmation of target DNA- and $\mathrm{pH}$-responsive DNA hydrogels}

To form target DNA- and pH-responsive DNA hydrogels, the target DNA and three HDs were incubated together in $1 \mathrm{X} \mathrm{PBS}$ at $\mathrm{pH} 7.4$ for $1 \mathrm{~h}$ at room temperature. The $\mathrm{pH}$ of the resultant solutions was lowered from $\mathrm{pH} 7.4$ to $\mathrm{pH} 5.0$ using $0.5 \mathrm{M} \mathrm{HCl}$. To visualize the gel state, $20 \mathrm{~nm}$ gold nanoparticles $(1 \mathrm{nM})$ stabilized in citrate buffer (Sigma-Aldrich, USA) were centrifuged at $14,000 \mathrm{rpm}$ for $10 \mathrm{~min}$ at $4{ }^{\circ} \mathrm{C}$, after which the supernatant was removed and concentrated to $10 \mathrm{nM}$. The gold nanoparticles $(5 \mu \mathrm{L})$ were then directly added to a mixture $(10 \mu \mathrm{L})$ of target DNA and HDs at room temperature. For scanning electron microscopy (SEM) analysis, the DNA hydrogels (prepared as described above) were placed on the SEM holder and then freeze-dried under vacuum for $2 \mathrm{~h}$. The resultant products were sputter-coated with platinum for $60 \mathrm{~s}$ and analyzed using an FE-SEM S-4200 (Hitachi Ltd., Japan).

\section{DNA hydrogel-based capillary assay for target DNA detection}

Equal moles of all HDs (HD1, HD2, and HD3) were mixed and then incubated in $0.2 \mathrm{~mL}$ PCR tubes (Axygen ${ }^{\circledR}$, USA) with various concentrations of target DNA at room temperature. After $1 \mathrm{~h}, 0.5 \mathrm{M} \mathrm{HCl}(0.3 \mu \mathrm{L})$ was added to the resultant solutions $(30 \mu \mathrm{L})$ to lower the $\mathrm{pH}$ from 7.4 to 5.0 over 1 min. Glass capillary tubes (Heinz ${ }^{\circledR}$ Micro Hematocrit Capillary Take, Germany) with dimensions of $1.55 \times 75 \mathrm{~mm}$ (diameter $\times$ height) were vertically immersed in the resultant solutions for $20 \mathrm{~s}$, and the liquid rise in the capillary tubes was estimated by a ruler. To evaluate the limit of detection (LOD), we added target DNA with different concentrations to the mixture of each HD $(100 \mu \mathrm{M})$ and incubated at room temperature for $1 \mathrm{~h}$. Images of the liquid levels inside the capillary tubes were analyzed using ImageJ software. The 
LOD was determined from a linear regression analysis of the calibration curve, as calculated by 3.29 times the slope of the regression line, which was divided by the standard deviation of the blank sample measurements $(n=10)$. To confirm the selectivity of the assay for the target gene in serum samples with different genes, $100 \mu \mathrm{M}$ of HDs and $100 \mu \mathrm{M}$ of different genes ( $E$ gene, $K P C$ gene, $H C V$ gene, and miRNA 34 ) were mixed in $1 \mathrm{X}$ PBS containing $10 \%$ serum (Thermo Fisher Gibco $^{\text {TM }}$, USA) at pH 7.4. Then, $100 \mu \mathrm{M}$ of target DNA was added to the resultant solution and incubated for $1 \mathrm{~h}$ at room temperature, and the $\mathrm{pH}$ value was adjusted from 7.4 to 5.0 using $0.5 \mathrm{M} \mathrm{HCI}$. After $1 \mathrm{~min}$, glass capillary tubes were used to measure the liquid rise.

\section{Results and discussion}

\section{Design of target DNA- and pH-responsive DNA hydrogel-based capillary assay}

The principle of the developed target DNA- and pH-responsive DNA hydrogel-based capillary assay is schematically shown in Fig. 1. Three kinds of catalytic hairpin DNA (HD), namely HD1, HD2, and HD3, are rationally designed to have two half-complementary sequences to each other so that an equal amount of HD can be self-assembled to produce well-defined Y-shaped DNA nanostructures (Y-DNA) in the presence of single-stranded target DNA (TD) via CHA cycling reactions. The HD is composed of four regions: two single-stranded toeholds at the $3^{\prime}$ end $(9 \mathrm{nt})$ and the $5^{\prime}$ end (11 nt, black color), a double-stranded stem (15 bp), and a single-stranded loop (12 nt). Notably, the toehold at the 5' end of each HD synthesizes cytosine (C)-rich sequences, providing the means to physically form intercalated-motif DNA (i-motif DNA) structures as a crosslinker under acidic conditions via self-assembly with each other [20-23]. In this assay, we employ 24 nt short complementary TD targeting the $N$ gene of the SARS-CoV-2 RNA genome [24, $25]$. In the presence of TD, the toehold at the $3^{\prime}$ end and the stem of HD1 completely hybridize with the TD to generate TD + HD1 products with new sticky ends (38 nt), which further interact with the toehold at the $3^{\prime}$ end and stem of HD2 to form TD $+\mathrm{HD} 1+\mathrm{HD} 2$ products. Similarly, HD3 binds to the resultant TD $+\mathrm{HD} 1+\mathrm{HD} 2$ products to produce the final products, Y-DNA, which simultaneously dissociates from the TD because of competitive hybridization [26, 27]. The released TD participates again in the CHA cycling reactions, enabling the continuous production of Y-DNA until the HDs are exhausted completely. The resultant Y-DNA consists of a double-stranded three-way junction ( $24 \mathrm{bp}$ ) as the core and three sticky ends (14 nt) bearing C-rich sequences in the arms, which serve as a building block to form DNA hydrogels under acidic conditions via i-motif-driven selfassembly. When the DNA hydrogels are formed, the liquid

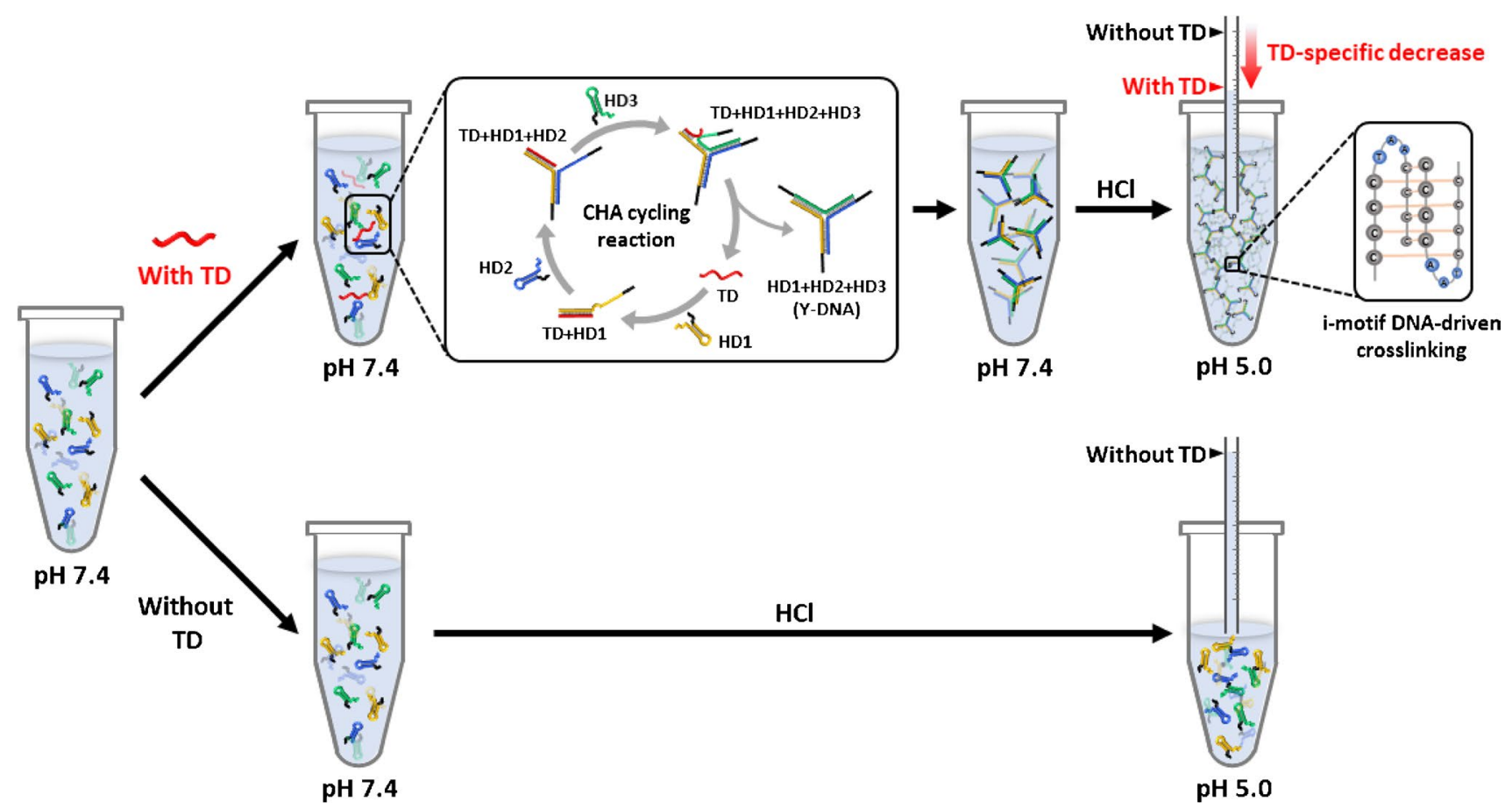

Fig. 1 Schematic illustration of the target DNA- and pH-sensitive DNA hydrogel-based capillary assay for the naked eye detection of short single-stranded target DNA. TD, target DNA; CHA, catalytic hairpin assembly; i-motif DNA, intercalated-motif DNA 
solution turns into mildly flowing gel states with high viscosity due to their water-holding property [28-30], which causes a noticeable decrease in the volume of the rising liquid driven by capillary action inside a capillary tube when vertically inserted into the solution. In the absence of TD, the HDs do not participate in the CHA cycling reactions under the same conditions, which results in no significant decrease in the liquid volume inside the capillary tubes. In this way, we can adopt a capillary tube as a visual indicator for the naked eye detection of target DNA at room temperature without any enzymatic amplification, polymers, or special equipment via the developed DNA hydrogel-based capillary assay.

\section{Optimization of HD structures and TD length for fabricating the CHA-mediated Y-DNA}

To verify the feasibility of our assay, we first optimized the structure of the HD that participates in the CHA cycling reactions to form Y-DNA in the presence of TD (Fig. S1). A variety of HD structures were designed by adjusting the length of the toehold at the $3^{\prime}$ end and the stem: $\mathrm{HD}_{\mathrm{X}-\mathrm{Y}}$, where $X$ and $Y$ denote the number of toehold sequences at the $3^{\prime}$ end $(X=6,7,8,9)$ and the stem sequences $(Y=18$, $17,16,15)$, respectively. Each resultant HD showed a bright single band, indicating monodisperse and well-defined hairpin structures without non-specific aggregation. Upon the addition of $\mathrm{TD}, \mathrm{HD}_{6-18}$ and $\mathrm{HD}_{7-17}$ showed no remarkable band shifts (Fig. S1b, line 5) as compared to their composites, while a new band that migrated slowly was observed in $\mathrm{HD}_{8-16}$. However, in the case of $\mathrm{HD}_{9-15}$, there were three distinct new bands with different molecular weights under the same conditions. This result strongly suggests that the toehold length of the HD plays an important role in opening its stem to initiate the CHA cycling reactions upon contact with TD, thus enabling the formation of stable Y-DNA nanostructures.

We further investigated whether the observed band shift of $\mathrm{HD}_{9-15}$ indeed indicated Y-DNA products by initiating the stepwise self-assembly of three individual $\mathrm{HD}_{9-15}$ (Fig. 2a). Upon mixing of TD and HD $1_{9-15}$, PAGE analysis exhibited only one bright new band (Fig. 2a, line 5) as compared to its components (Fig. 2a, lines 1 and 2), indicating the successful hybridization of $\mathrm{TD}+\mathrm{HD} 1_{9-15}$ products. Upon a subsequent addition of $\mathrm{HD} 2_{9-15}$ into the TD + HD $1_{9-15}$ products, a new band related to $\mathrm{TD}+\mathrm{HD} 1_{9-15}+\mathrm{HD} 2_{9-15}$ products appeared (Fig. 2a, line 6), indicating the successful formation of one arm of Y-DNA. Finally, following incubation with $\mathrm{HD} 3_{9-15}$, the $\mathrm{TD}+\mathrm{HD} 1_{9-15}+\mathrm{HD} 2_{9-15}$ products migrated much more slowly, forming a new band related to the Y-DNA products, HD1 $1_{9-15}+\mathrm{HD} 2_{9-15}+\mathrm{HD} 3_{9-15}$ (Fig. 2a, line 7). However, when mixing all three $\mathrm{HD}_{9-15}$ together without adding TD, no significant band shift was observed under the same conditions (Fig. 2a, line 8). Consequently, it can be said that the observed band shifts were clearly caused by the programmable self-assembly of $\mathrm{HD}_{9-15}$. Importantly, the electrophoretic mobility of the resultant Y-DNA products was exactly consistent with the results of mixing TD with the three $\mathrm{HD}_{9-15}$ (Fig. S1, line 5), demonstrating that the Y-DNA products were successfully synthesized from the three $\mathrm{HD}_{9-15}$ according to the designed scheme (Fig. 1). We then estimated the minimum TD length to fabricate stable a)

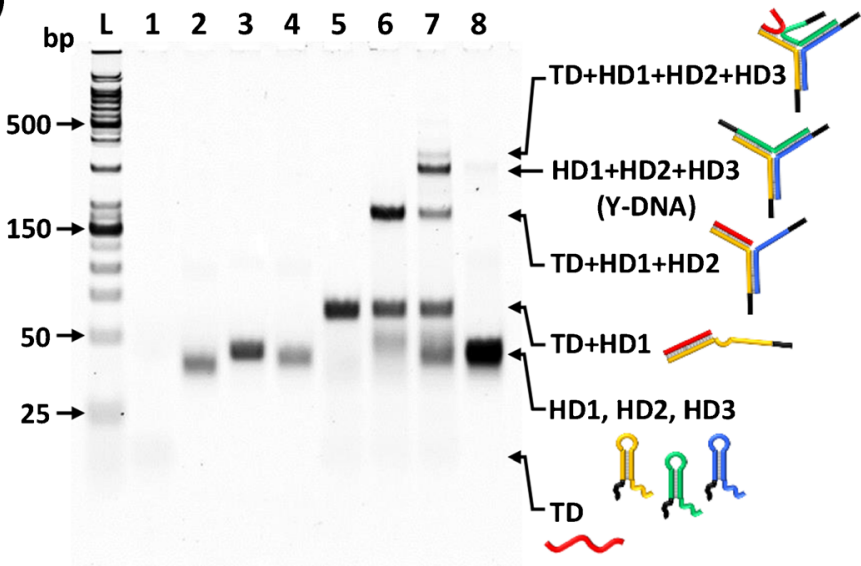

b)

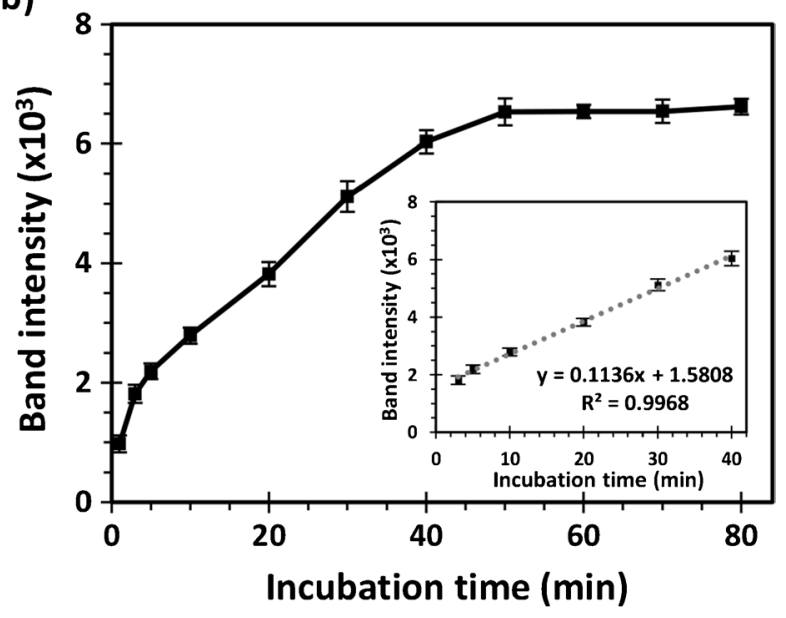

Fig. 2 a PAGE analysis to confirm the formation of Y-DNA products via the proposed TD-mediated CHA cycling reactions. TD, target DNA; HD, hairpin DNA. Line L: ladder; Line 1: TD; Line 2: HD1; Line 3: HD2; Line 4: HD3; Line 5: TD+HD1; Line 6: $\mathrm{TD}+\mathrm{HD} 1+\mathrm{HD} 2$; Lines 7 and 8: mixture of HD1+HD2+HD3 in the presence/absense of TD, respectively. b Time-dependent profile of the gel band intensity of the amplified Y-DNA products upon mixing HD and TD at a 1:0.5 molar ratio. Inset: Linear plot of the gel band intensity at different incubation times ranging from 3 to $40 \mathrm{~min}$ 
Y-DNA products by incubating three $\mathrm{HD}_{9-15}$ and $\mathrm{TD}$ with different lengths of 22, 23, 24, 25, and 26 nt. A significant band shift was observed in over $24 \mathrm{nt}$ TD compared to that of 22 and 23 nt TD (Fig. S2). Thus, we selected $\mathrm{HD}_{9-15}$ and $24 \mathrm{nt} \mathrm{TD}$ as the optimized HD structure and target length, respectively, for the TD-mediated CHA cycling reactions to produce Y-DNA products.

\section{Cycling efficiency of TD-mediated CHA reactions}

To evaluate the cycling efficiency of TD in the CHA reactions, we examined the amount of Y-DNA products generated from a mixture of $100 \mathrm{nM}$ HD and $50 \mathrm{nM}$ TD over time by analyzing gel band intensities. As shown in Fig. 2b, with increasing incubation time, the synthesized Y-DNA products gradually increased and reached a plateau at approximately $50 \mathrm{~min}$. We note the remarkable linear relationship between the Y-DNA products and incubation time exhibited in the range from 3 to $40 \mathrm{~min}$. In this relationship, the correlation equation is fitted as $Y=0.1136 X+1.5808\left(R^{2}=0.9968\right)$, indicating that about $0.4 \mathrm{nM}$ of the Y-DNA products per minute was produced via the proposed TD-mediated CHA cycling reactions. This result provides evidence that TD serves as a recyclable catalyst to continuously synthesize Y-DNA products without precise temperature control or enzymatic reactions. Thus, it was confirmed that even at low concentrations of TD, the developed assay can sufficiently amplify Y-DNA via CHA recycling reactions.

\section{Confirmation of target DNA- and pH-responsive DNA hydrogels}

To explore the formation of the target DNA- and pH-responsive DNA hydrogels, we optimized the concentration of the $\mathrm{HD}$ and the $\mathrm{pH}$ value. DNA hydrogels were prepared by mixing $\mathrm{HD}$ and TD in a 1:1 molar ratio at $\mathrm{pH} 7.4$ and then successively lowering the $\mathrm{pH}$ to 6.0, 5.0, 4.0, and 3.0. The capillary liquid height gradually decreased, reached its lowest level at $\mathrm{pH}$ 5.0, and then gradually increased until pH 3.0 (Fig. S3). As shown in Fig. 3, with increasing concentrations ranging from 0 to $300 \mu \mathrm{M} \mathrm{HD}$ at $\mathrm{pH} 5.0$, the liquid levels inside capillary tubes gradually decreased and reached a plateau at $100 \mu \mathrm{M}$. The average liquid heights by concentration inside the tubes were $1.83 \pm 0.03 \mathrm{~cm}$ at $0 \mu \mathrm{M}$ $\mathrm{HD}, 1.28 \pm 0.04 \mathrm{~cm}$ at $50 \mu \mathrm{M} \mathrm{HD}, 0.97 \pm 0.03 \mathrm{~cm}$ at $100 \mu \mathrm{M}$ $\mathrm{HD}, 0.94 \pm 0.06 \mathrm{~cm}$ at $200 \mu \mathrm{M} \mathrm{HD}$, and $0.9 \pm 0.05 \mathrm{~cm}$ at $300 \mu \mathrm{M}$ HD. Consequently, we chose $100 \mu \mathrm{M}$ and pH 5.0 as the optimized $\mathrm{HD}$ concentration and $\mathrm{pH}$ value, respectively, for the TD-mediated DNA hydrogel-based capillary assay. We then evaluated the viscosity of the resultant products prepared by mixing HD and TD at different concentrations ranging from $0 \mathrm{pM}$ to $100 \mu \mathrm{M}$. With increasing TD concentration, the products exhibited more stable gel structures (Fig. S4, upper panel). In addition, after dropping the resultant products onto a plate glass, their average surface areas gradually decreased to $45.9 \pm 0.6 \mathrm{~mm}^{2}$ at $0 \mathrm{pM}, 34.3 \pm 0.9$ $\mathrm{mm}^{2}$ at $50 \mathrm{pM}, 27.7 \pm 0.5 \mathrm{~mm}^{2}$ at $1 \mu \mathrm{M}$, and $23.2 \pm 0.9 \mathrm{~mm}^{2}$ at $100 \mu \mathrm{M}$, due to increased gel viscosity (Fig. S4, lower panel).

Next, to examine whether the observed changes in the liquid levels inside the capillary tubes were caused by DNA hydrogels, gold nanoparticles (GNPs) were used as an indicator to visualize the formation of DNA hydrogels in the solution due to their bright color and water-soluble properties (Fig. 4a) [20]. Upon the addition of GNPs in a mixture of TD and $\mathrm{HD}$ at $\mathrm{pH}$ 5.0, the GNPs were not dispersed evenly but located on the upper layer of the solution (Fig. 4a, upper right panel), resulting in a separated layer. On

\section{Concentration of HD}

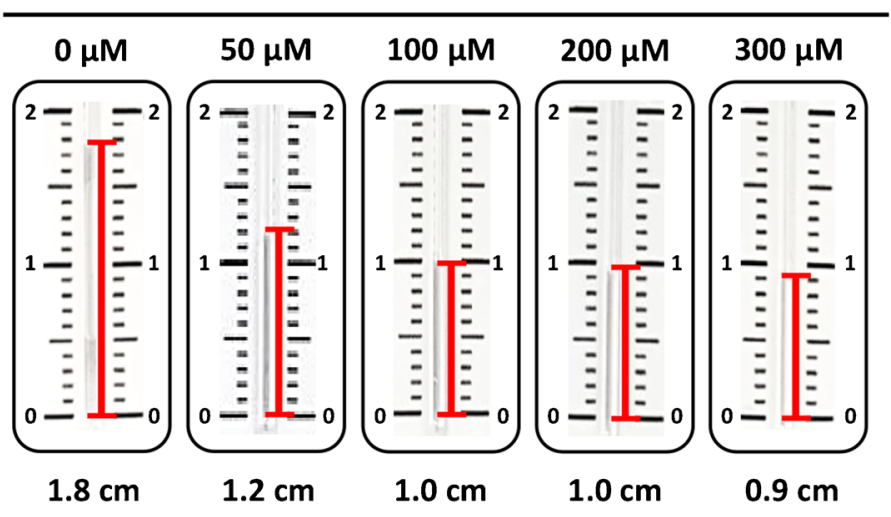

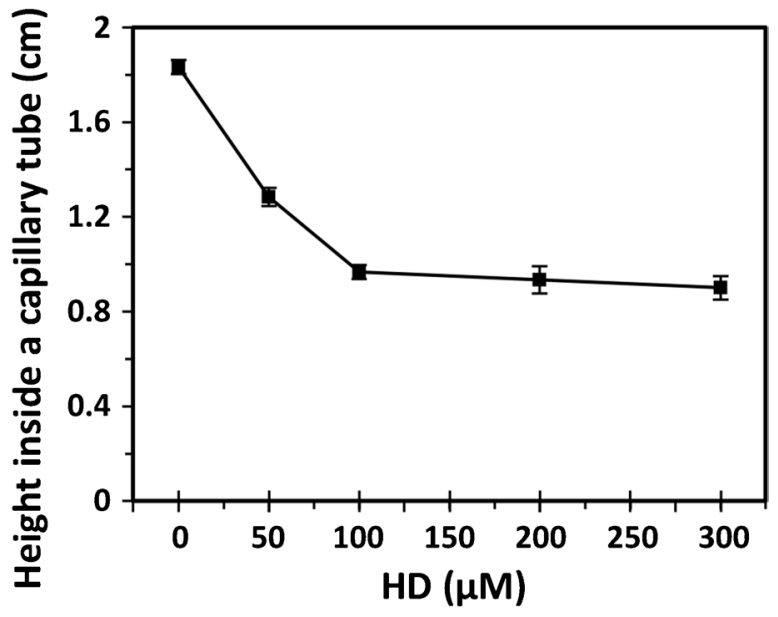

Fig. 3 Optimization of HD concentration for the developed assay. Representative photographs of capillary tubes (left panel) and corresponding liquid heights inside the capillary tubes (right panel) upon insertion into a mixture of HD and TD at a 1:1 molar ratio, $\mathrm{pH} 5.0$ 


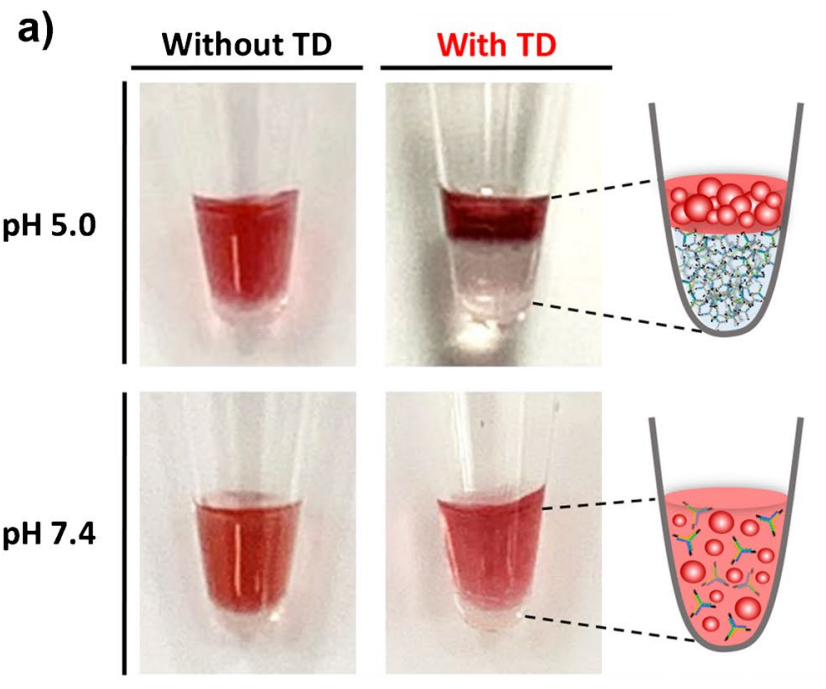

Fig. 4 Confirmation of target DNA- and pH-responsive DNA hydrogels. a Photographs of solutions in the absence and presence of target DNA at pH 7.4 and pH 5.0 after adding $20 \mathrm{~nm}$ gold nanoparticles. b

the other hand, in a mixture at $\mathrm{pH} 7.4$, the GNPs uniformly dispersed throughout the whole solution and retained a red color (Fig. 4a, lower right panel). In the absence of TD, no separated layers and no color change were observed in the solutions at either $\mathrm{pH} 5.0$ or $\mathrm{pH} 7.4$ under the same conditions (Fig. 4a, upper and lower left panels). For further confirmation, scanning electron microscopy (SEM) analysis was performed after freeze-drying the solutions (Fig. 4b). The lyophilized products of the HD and TD solution at $\mathrm{pH} 5.0$ showed compact and dense network structures. In contrast, in the absence of TD, the lyophilized products exhibited relatively large-sized and irregular porous structures with a sponge-like surface porosity under the same conditions, a tendency similarly seen in the HD solutions with and without TD at $\mathrm{pH}$ 7.4. These results strongly indicate the successful fabrication of target DNA- and $\mathrm{pH}-$ responsive DNA hydrogels by combining CHA-mediated Y-DNA synthesis and i-motif-driven self-assembly.

\section{Target DNA detection in the DNA hydrogel-based capillary assay}

To demonstrate the assay's detection sensitivity of target DNA, the liquid levels inside the capillary tubes were evaluated at various concentrations of TD (Fig. 5). With increasing TD concentrations from $0 \mathrm{pM}$ to $100 \mu \mathrm{M}$, the liquid heights gradually decreased, which indicates that the proposed DNA hydrogel-based capillary assay is highly dependent on the concentration of the target DNA and therefore can be used for the quantitative detection of target DNA. The average liquid heights inside the capillary tubes by TD concentration were $1.57 \pm 0.03 \mathrm{~cm}$ at $0 \mathrm{pM}, 1.57 \pm 0.03 \mathrm{~cm}$ b)

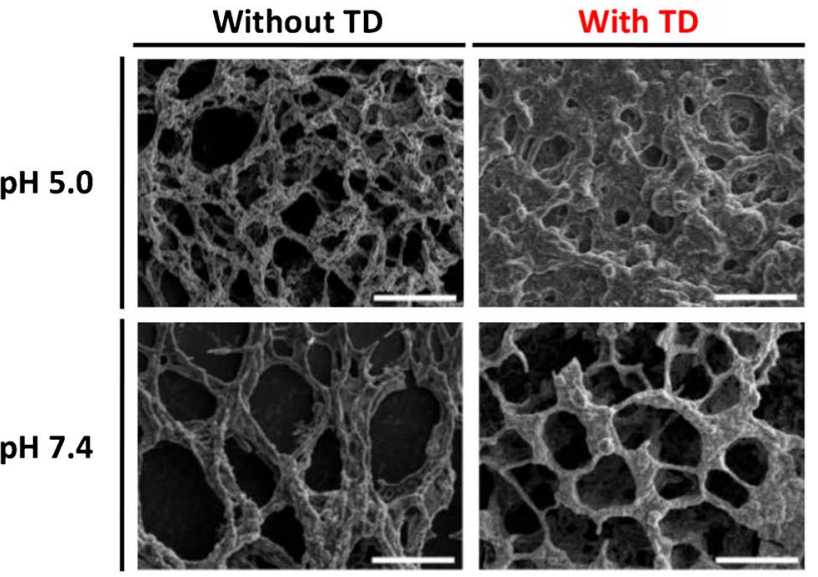

SEM images of the hydrated products in the solutions in the absence and presence of target DNA at pH 7.4 and pH 5.0. Scale bar: $300 \mu \mathrm{m}$

at $10 \mathrm{pM}, 1.53 \pm 0.03 \mathrm{~cm}$ at $50 \mathrm{pM}, 1.47 \pm 0.02 \mathrm{~cm}$ at $100 \mathrm{pM}, 1.43 \pm 0.04 \mathrm{~cm}$ at $150 \mathrm{pM}, 1.37 \pm 0.03 \mathrm{~cm}$ at $200 \mathrm{pM}, 1.35 \pm 0.03 \mathrm{~cm}$ at $1 \mathrm{nM}, 1.32 \pm 0.03 \mathrm{~cm}$ at $10 \mathrm{nM}, 1.3 \pm 0.05 \mathrm{~cm}$ at $50 \mathrm{nM}, 1.27 \pm 0.01 \mathrm{~cm}$ at $100 \mathrm{nM}, 1.2 \pm 0.03 \mathrm{~cm}$ at $200 \mathrm{nM}, 1.2 \pm 0.04 \mathrm{~cm}$ at $1 \mu \mathrm{M}$, $1.07 \pm 0.03 \mathrm{~cm}$ at $10 \mu \mathrm{M}$, and $0.97 \pm 0.03 \mathrm{~cm}$ at $100 \mu \mathrm{M}$. In these results, a good linear relationship was obtained in the TD concentrations ranging from 10 to $200 \mathrm{pM}$. The plot was fitted by the equation $Y=-0.001 X+1.5797\left(R^{2}=0.9906\right)$, where $Y$ is the liquid height inside a capillary tube and $X$ is the TD concentration. From a linear regression analysis, the limit of detection (LOD) was calculated to be approximately $10 \mathrm{pM}$. In addition, the same capillary behavior was observed in the detection of $E$ gene target cDNA of SARSCoV-2 RNA (Fig. S5), indicating that the developed assay can potentially be utilized as a promising platform to detect other target genes of interest. Compared with other enzymefree assays, the developed assay demonstrated comparable sensitivity and detection time (Table S2).

\section{Sequence-specific detection of the DNA hydrogel- based capillary assay}

Sequence-specific detection with the developed assay was examined by measuring the liquid levels inside capillary tubes in mixtures of HD and various TD mutants under acidic conditions (Fig. 6a). The TD mutants had homologous sequences with the TD: one-, two-, three-, and multiple-base mismatched TD and non-complementary TD (OM TD, DM TD, TM TD, MM TD, and NC TD, respectively). As compared to the height in the absence of $\mathrm{TD}(1.57 \pm 0.03 \mathrm{~cm})$, the liquid height was significantly 
Fig. 5 a Representative photographs of capillary tubes with remarkable scale changes at different concentrations of target DNA (TD) ranging from $0 \mathrm{pM}$ to $100 \mu \mathrm{M}$. b Linear relationship between the liquid heights inside the capillary tubes and different concentrations of TD ranging from 0 to $200 \mathrm{pM}$ a)

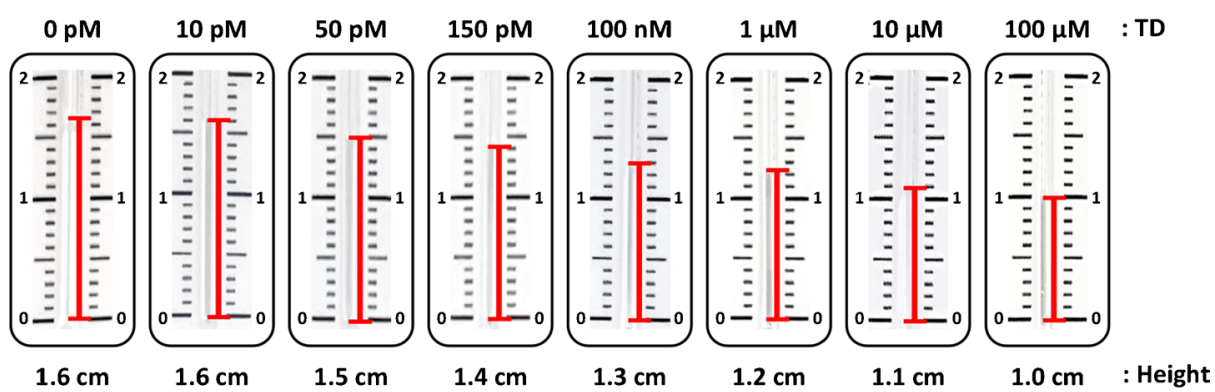

b)

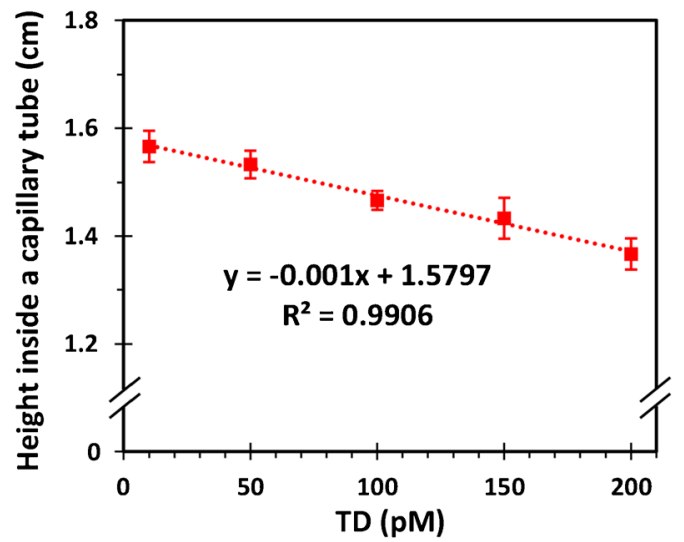

a)

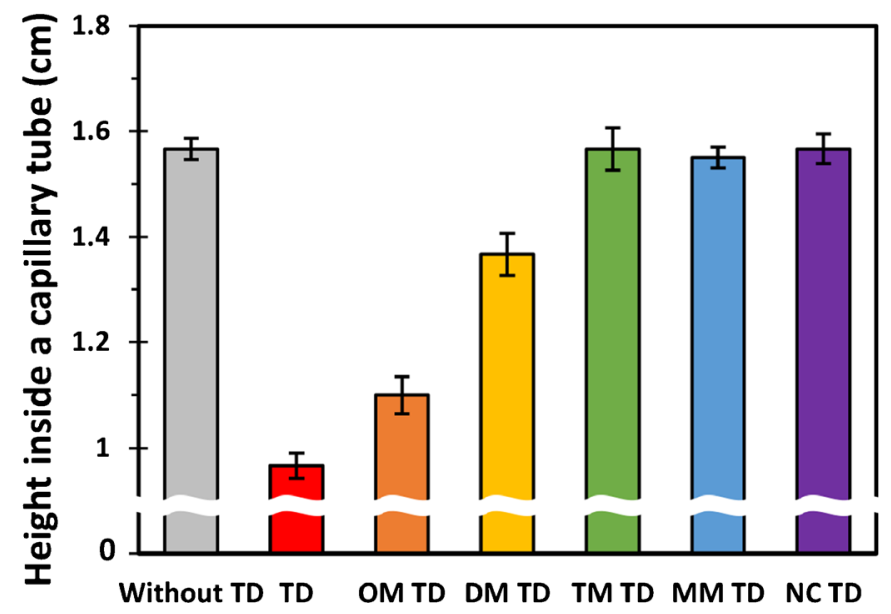

b)

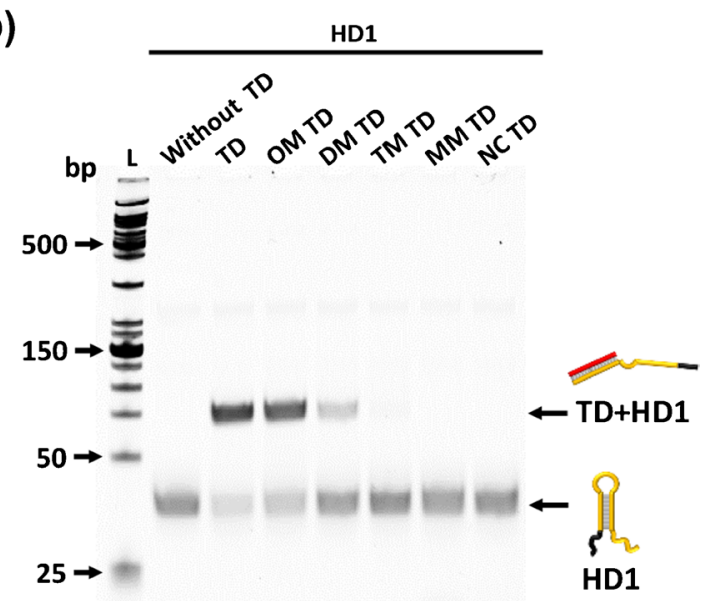

TD : CTT CCT CAA GGA ACA ACA TTG CCA OM TD : CTT CCA CAA GGA ACA ACA TTG CCA DM TD : CTT CCA CAA GGA TCA ACA TTG CCA TM TD : CTT CCA CAA GGA TCA ACA ATG CCA MM TD : CTT CCA CAA CGA TCA TCA ATG CCA NC TD : CAC CCA TGG ACA CAC CCA TCC GTT
Fig. 6 Confirmation of sequence specificity. a Liquid heights inside capillary tubes in a mixture of HD and various target DNA mutants at a 1:1 molar ratio, $\mathrm{pH}$ 5.0. b PAGE analysis to confirm the hybridization between HD1 and the various target DNA mutants. TD, $N$ gene

reduced to $0.97 \pm 0.03 \mathrm{~cm}$ for the perfectly matched TD, $1.1 \pm 0.05 \mathrm{~cm}$ for $\mathrm{OM} \mathrm{TD}$, and $1.37 \pm 0.06 \mathrm{~cm}$ for $\mathrm{DM}$ TD. However, no remarkable change in the liquid volume target cDNA; OM TD, one-base mismatched TD; DM TD, two-base mismatched TD; TM TD, three-base mismatched TD; MM TD, multiple-base mismatched TD; NC TD, non-complementary TD. The red text indicates mismatched bases

was observed in the TM TD $(1.57 \pm 0.06)$, MM TD $(1.55 \pm 0.03 \mathrm{~cm})$, or NC TD $(1.57 \pm 0.03 \mathrm{~cm})$ under the same conditions. In addition, PAGE analysis also showed 
noticeable band shifts when mixing HD1 with TD, OM TD, and DM TD as compared to its composites, whereas TM TD, MM TD, and NC TD did not show band shifts (Fig. 6b). These results indicate that the sequence specificity of the developed assay can be attributed to the stemopening of HD1, which can dissociate the stable basepairing of the stem by one- and two-mismatched sequences from the target DNA. Accordingly, the developed assay can accurately discriminate three or more mismatched sequences from the target DNA.

\section{Analyzing the DNA hydrogel-based capillary assay in serum containing different genes}

To evaluate the practical application of our assay, we carried out $N$ gene TD detection in $10 \%$ serum samples containing different types of genes, namely $E$ gene, $K P C$ gene, $H C V$ gene, and miRNA 34 at pH 5.0. As shown in Fig. 7, no noticeable decrease in the liquid heights inside the capillary tubes was observed in the serum $(1.54 \pm 0.02 \mathrm{~cm})$ containing different genes without $N$ gene TD, which is similar to the results of the PBS solution $(1.55 \pm 0.04 \mathrm{~cm})$ without serum under the same conditions. This result indicates that the serum did not affect the detection of TD in the developed assay. Significant decreases in the serum $(0.93 \pm 0.03 \mathrm{~cm})$ and PBS $(0.94 \pm 0.04 \mathrm{~cm})$ samples containing different genes and $N$ gene TD indicate that the developed assay was able to successfully achieve a high selectivity for the TD in complex biological samples.

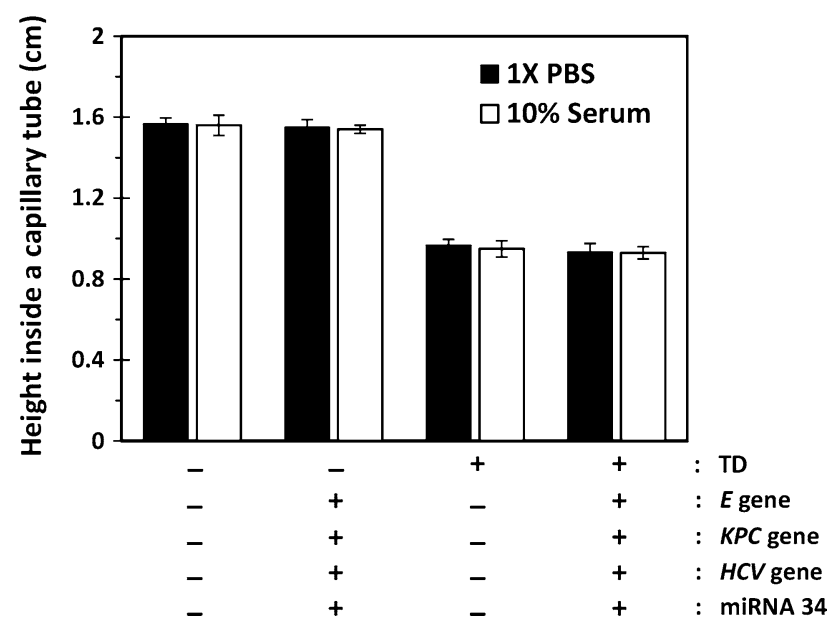

Fig. 7 Target DNA detection in serum samples containing different types of genes: $E$ gene, $K P C$ gene, $H C V$ gene, and miRNA 34 . The heights inside the capillary tubes were determined upon insertion into $10 \%$ serum samples containing $100 \mu \mathrm{M}$ HDs and $100 \mu \mathrm{M}$ of the different genes at $\mathrm{pH}$ 5.0. KPC, Klebsiella pneumoniae carbapenemase; $\mathrm{HCV}$, hepatitis $\mathrm{C}$ virus

\section{Conclusion}

We have successfully developed a target DNA- and $\mathrm{pH}$ responsive DNA hydrogel-based capillary assay to detect short single-stranded target DNA as a simple, low-cost, and user friendly naked eye detection platform. The catalytic hairpin DNA assembly technique was proposed to generate sufficient amounts of Y-shaped DNA nanostructures in the presence of extremely small amounts of target DNA. The amplified Y-DNA is composed of i-motif DNA-forming sticky ends at each arm, which can be self-assembled under acidic conditions to form target DNA- and $\mathrm{pH}$-responsive DNA hydrogels. When inserting a capillary tube in the solution, the capillary action-induced liquid rise highly depends on the concentrations of the target DNA, which enables one to sensitively and quantitatively detect target DNA with the naked eye without requiring expensive analytic equipment or complex operations. Notably, the developed assay exhibited a high sensitivity of target gene detection in serum conditions and was shown to be effectively applied to detect target genes of interest. Owing to this, we expect that the developed assay can be potentially utilized to detect a variety of single-stranded DNA oligomers as a simple and economic POC testing platform for clinical diagnostics. We note that the developed assay is at present incapable of accurately distinguishing one- and two-base mismatches in target DNA. To address this point, we are currently working on a followup study focusing on target gene screening for sequencespecific recognition and the opening of DNA hairpin loops for specificity improvement.

Supplementary Information The online version contains supplementary material available at https://doi.org/10.1007/s00604-021-05138-9.

Funding This work was supported by a National Research Foundation of Korea (NRF) grant (NRF-2019R1G1A1099674) funded by the Korean government (Ministry of Science and ICT).

\section{Declarations}

Conflict of interest The authors declare no competing interests.

\section{References}

1. Lockhart DJ, Winzeler EA (2000) Genomics, gene expression and DNA arrays. Nature 405:827-836. https://doi.org/10.1038/35015 701

2. Kim RY, Xu H, Myllykangas S, Ji H (2011) Genetic-based biomarkers and next-generation sequencing: the future of personalized care in colorectal cancer. Per Med 8:331-345. https://doi.org/ 10.2217/pme.11.16

3. Ziegler A, Koch A, Krockenberger K, Großhennig A (2012) Personalized medicine using DNA biomarkers: a review. Hum Genet 131:1627-1638. https://doi.org/10.1007/s00439-012-1188-9 
4. Page DB et al (2016) Deep sequencing of T-cell receptor DNA as a biomarker of clonally expanded TILs in breast cancer after immunotherapy. Cancer Immunol Res 4:835-844. https://doi.org/ 10.1158/2326-6066.cir-16-0013

5. Afonina I, Zivarts M, Kutyavin I, Lukhtanov E, Gamper H, Meyer RB (1997) Efficient priming of PCR with short oligonucleotides conjugated to a minor groove binder. Nucleic Acids Res 25:26572660. https://doi.org/10.1093/nar/25.13.2657

6. Liu J, Zhang Y, Xie H, Zhao L, Zheng L, Ye H (2019) Applications of catalytic hairpin assembly reaction in biosensing. Small 15:1902989. https://doi.org/10.1002/smll.201902989

7. He $\mathrm{H}$ et al (2016) Target-catalyzed autonomous assembly of dendrimer-like DNA nanostructures for enzyme-free and signal amplified colorimetric nucleic acids detection. Biosens Bioelectron 86:985-989. https://doi.org/10.1016/j.bios.2016.07.045

8. Park C, Song Y, Jang K, Choi CH, Na S (2018) Target switching catalytic hairpin assembly and gold nanoparticle colorimetric or EGFR mutant detection. Sens Actuators B Chem 261:497-504. https://doi.org/10.1016/j.snb.2018.01.183

9. Park C, Park H, Lee HJ, Lee HS, Park KH, Choi CH, Na S (2019) Double amplified colorimetric detection of DNA using gold nanoparticles, enzymes and a catalytic hairpin assembly. Microchim Acta 186:34. https://doi.org/10.1007/s00604-018-3154-2

10. Ye T, Peng Y, Yuan M, Cao H, Yu J, Li Y, Xu F (2019) Targetinduced in-situ formation of fluorescent DNA-templated copper nanoparticles by a catalytic hairpin assembly: application to the determination of DNA and thrombin. Microchim Acta 186:760. https://doi.org/10.1007/s00604-019-3927-2

11. He Z, Wu J, Qiao B, Pei H, Xia Q, Wu Q, Ju H (2020) Targetcatalyzed assembly of pyrene-labeled hairpins for exponentially amplified biosensing. ACS Appl Bio Mater 3:5342-5349. https:// doi.org/10.1021/acsabm.0c00658

12. Liu X, Zhou X, Xia X, Xiang H (2020) Catalytic hairpin assembly-based double-end DNAzyme cascade-feedback amplification for sensitive fluorescence detection of HIV-1 DNA. Anal Chim Acta 1096:159-165. https://doi.org/10.1016/j.aca.2019.10.051

13. Bodulev OL, Burkin KM, Efremov EE, Sakharov IY (2020) One-pot microplate-based chemiluminescent assay coupled with catalytic hairpin assembly amplification for DNA detection. Anal Bioanal Chem 412:5105-5111. https://doi.org/10.1007/ s00216-020-02438-6

14. Do JY, Jeong JY, Hong CA (2021) Catalytic hairpin DNA assembly-based chemiluminescent assay for the detection of short SARS-CoV-2 target cDNA. Talanta 233:122505. https://doi.org/ 10.1016/j.talanta.2021.122505

15. Ren R, Bi Q, Yuan R, Xiang Y (2020) An efficient, label-free and sensitive electrochemical microRNA sensor based on target-initiated catalytic hairpin assembly of trivalent DNAzyme junctions. Sens Actuators B Chem 304:127068. https://doi.org/10.1016/j. snb.2019.127068

16. Li Y, Men X, Gao G, Tian Y, Wen Y, Zhang W (2021) A distancebased capillary biosensor using wettability alteration. Lab Chip 21:719-724. https://doi.org/10.1039/d0lc01147a

17. Li Y, Ma Y, Jiao X, Li T, Lv Z, Yang CJ, Zhang X, Wen Y (2019) Control of capillary behavior through target-responsive hydrogel permeability alteration for sensitive visual quantitative detection. Nat Commun 10:1036. https://doi.org/10.1038/ s41467-019-08952-1

18. Jiang C, Li Y, Wang H, Chen D, Wen Y (2020) A portable visual capillary sensor based on functional DNA crosslinked hydrogel for point-of-care detection of lead ion. Sens Actuators B Chem 307:127625. https://doi.org/10.1016/j.snb.2019.127625

19. Wang H, Wang H, Li Y, Jiang C, Chen D, Wen Y, Li Z (2020) Capillarity self-driven DNA hydrogel sensor for visual quantification of microRNA. Sens Actuators B Chem 313:128036. https:// doi.org/10.1016/j.snb.2020.128036

20. Cheng E et al (2009) A pH-triggered, fast-responding DNA hydrogel. Angew Chem Int Ed 48:7660-7663. https://doi.org/10.1002/ anie. 200902538

21. Guo W, Lu CH, Orbach R, Wang F, Qi XJ, Cecconello A, Selik$\operatorname{tar} \mathrm{D}$, Willner I (2015) pH-stimulated DNA hydrogels exhibiting shape-memory properties. Adv Mater 27:73-78. https://doi.org/ 10.1002/adma.201403702

22. Xu W, Huang Y, Zhao H, Li P, Liu G, Li J, Zhu C, Tian L (2017) DNA hydrogel with tunable $\mathrm{pH}$-responsive properties produced by rolling circle amplification. Chem Eur J 23:18276-18281. https:// doi.org/10.1002/chem.201704390

23. Shi L, Peng P, Du Y, Li T (2017) Programmable i-motif DNA folding topology for a $\mathrm{pH}$-switched reversible molecular sensing device. Nucleic Acids Res 45:4306-4314. https://doi.org/10.1093/ nar/gkx202

24. Kakhki RK, Kakhki MK, Neshani A (2020) COVID-19 target: a specific target for novel coronavirus detection. Gene Rep 20:100740. https://doi.org/10.1016/j.genrep.2020.100740

25. Corman VM et al (2020) Detection of 2019 novel coronavirus (2019-nCoV) by real-time RT-PCR. Euro Surveill 25:2000045. https://doi.org/10.2807/1560-7917.ES.2020.25.3.2000045

26. Yin P, Choi HMT, Calvert CR, Pierce NA (2008) Programming biomolecular self-assembly pathways. Nature 451:318-322. https://doi.org/10.1038/nature06451

27. Li B, Jiang Y, Chen X, Ellington AD (2012) Probing spatial organization of DNA strands using enzyme-free hairpin assembly circuits. J Am Chem Soc 134:13918-13921. https://doi.org/ 10.1021/ja300984b

28. Xing Z et al (2018) Microrheology of DNA hydrogels. Proc Natl Acad Sci USA 115:8137-8142. https://doi.org/10.1073/pnas. 1722206115

29. Morya V, Walia S, Mandal BB, Ghoroi C, Bhatia D (2020) Functional DNA based hydrogels: development, properties and biological applications. ACS Biomater Sci Eng 6:6021-6035. https://doi. org/10.1021/acsbiomaterials.0c01125

30. Iqbal S, Ahmed F, Xiong H (2021) Responsive-DNA hydrogel based intelligent materials: preparation and applications. Chem Eng J 420:130384. https://doi.org/10.1016/j.cej.2021.130384

Publisher's note Springer Nature remains neutral with regard to jurisdictional claims in published maps and institutional affiliations. 